\title{
Solar Energy Entrepreneurship to Promote Universal Electricity Access in Rural India: Challenges and Opportunities
}

\author{
D. V. Avasthi \\ Professor, Department of Electronics \& Communication, Subharti Institute of Technology \& Engineering: SVSU; Meerut, Uttar Pradesh, \\ India
}

\begin{abstract}
The aim of this article is to motivate young Indian engineers to shun the craze and glamour for salaried employment in the metropolitan cities and instead, opt for the establishment and operation of micro and small, solar based, standalone micro-grid enterprises in villages to enhance rural electricity access in the country. The young engineers should volunteer active contribution to enhance rural electricity access and become job providers in their own enterprises instead of aspiring for jobs in metropolitan cities. The task of enhancing electricity access in rural India should become the top priority and a mass movement in India. The country should strive for universal access to electricity which should be realized through greater involvement of young engineering fraternity rather than letting it remain the cosmetic responsibility of Government machinery in the typical Indian style as is the scenario today. This paper, after introducing readers with the burning problem of energy poverty in rural India emphasizes development of standalone solar based micro-grid infrastructure for mitigation of the immediate electricity problem in rural India with future provision for its augmentation into a smart grid, ICT-enabled system introducing automation and additional user friendly features. An overview of energy entrepreneurship and facilitator agencies providing finance and solar skill training to the prospective engineer entrepreneurs is given along with brief information on subsidies, tax concessions and tax holidays under the National Solar Mission and MSME Scheme. The prospective young engineer entrepreneurs are urged to verify and supplement information provided in the text of this paper from the authentic information published by the facilitator agencies in order that the engineer entrepreneurs can optimize their profits. Given their resolve to eradicate energy poverty and sincere involvement in infrastructure development the universal access to energy in India shall not be a distant dream to realize. These endeavors are bound to bestow the youth engineer entrepreneur with career growth and financial prosperity besides simultaneously bringing economic development and prosperity to the country.
\end{abstract}

Keywords: Energy poverty, Standalone Micro-grid systems, Smart grid, Universal electricity access, MDGs

\section{Introduction}

Energy poverty in rural India is a hidden challenge eating into the vitals of Indian economy. Even after 68 years of national independence today, almost 300 million of the total 1.6 billion world population live without access to electricity in India $^{[1]}$. Majority among these depend on kerosene for lighting homes and biomass for cooking food, thus being exposed to environmental hazards and deadly respiratory diseases. Universal access to electricity is too much of a luxury for this segment of the Indian population reeling in abject poverty and deprivation due to the high cost of extending power grid in the remote village locations, poor economic health of the utilities and limited paying capacity of the peasants. Social justice demands that universal access to electricity be made the unfettered fundamental right of every citizen irrespective of one's location, rural or urban. Electricity is essential for human comfort, efficiency and basic needs like lighting, cooking food, cooling homes, earning a living and utilizing health and education services etc. In the absence of universal electricity access, the dream of digital India ${ }^{[2,3]}$, e-commerce, e-governance ${ }^{[4]}$ and smart cities and developed economy shall remain a farce and impossible to realize.

\section{Why to create Solar Micro-Grid in Villages?}

This paper, besides providing appraisal of the country's burning problem of energy poverty ${ }^{[1]}$, highlights the architecture of an innovative, off-grid solar based micro-grid system suitable for a rural dispensation and its possible transformation into the smart grid system bringing automation and additional user friendly features into the smart, ICT enabled system. The nuances of energy entrepreneurship are reviewed with an overview of the facilitator agencies providing finance and solar skill training to the young engineer entrepreneur. Upcoming enterprises in this category are eligible to avail subsidies, tax concession and tax holidays under the National Solar Mission and as MSMEs which is highlighted in the body text of the paper ${ }^{[5]}$. The prospective young engineer- entrepreneurs are urged to supplement information provided in the paper directly from the documentation published by the support agencies to optimize their profits from the electricity venture they choose to create. Given their resolve to eradicate energy poverty and sincere involvement in infrastructure development, the universal access to electricity in rural India shall not be a distant dream to realize. These endeavors are bound to bestow the youth with career growth and financial prosperity besides, simultaneously bringing economic development and prosperity to the nation.

This author, in some previous papers ${ }^{[6,7]}$, gave a clarion call to the young engineers to volunteer support for the creation and development of new, solar - energy based, micro-grid enterprises in rural India. The suggestion was made as the Government alone cannot rid masses from the dilemma of energy poverty and electricity starvation in rural India due to

\section{Volume 4 Issue 11, November 2015}




\section{International Journal of Science and Research (IJSR) \\ ISSN (Online): 2319-7064}

Index Copernicus Value (2013): 6.14 | Impact Factor (2014): 5.611

enormity of the problem. The solution lies in making eradication of energy poverty and enhancement of electricity infrastructure in rural India the Mission of the country and a mass movement. Suggestion for the solar - based enterprises was made, especially due to the availability of solar energy in abundance all over the country by virtue of its advantageous geographical location. India lies on the equatorial belt of the earth bestowing 250 to 300 clear sunny days in a year with annual global solar radiation from 1600 to $2200 \mathrm{KWh} / \mathrm{m}^{2}$ and equivalent energy potential of about 6,000 million $\mathrm{GWh}$ per year ${ }^{[8,9]}$. Energy from the sun alone can more than suffice the electricity needs of this country. Solar energy is a clean, emission free, renewable, affordable and environment friendly energy resource, abundantly available in India. The more it is harnessed to produce electricity, the better it shall be for larger electricity access on a countrywide scale. The country must gradually prepare itself to bid a good bye to the use of fossil fuels for electricity due to escalating costs of the imported fuel and the environmental degradation caused by the GHG and NOx emission generated by the fuels which has become a burning issue for the country's climate and sustainability. Optimal harnessing of solar energy for electricity can make this country the world leader in energy and bring this nation on the map of developed economies which all Indians should religiously strive for.

\section{Islanded Micro-Grid and Smart-Grid Architectures}

The advent of distributed generation in the power systems has aroused new hopes for accomplishing increased electricity access in geographically difficult or isolated pockets mostly located in rural India ${ }^{[10]}$. The rural micro-grid is a decentralized, modular and more flexible distributed energy system with distribution points located very near to the village cluster. Standalone Micro-grid systems of small power rating supplying electricity in remote village locations do not need large transmission line infrastructure as would be the case for conventional power system with centralized generation and lengthy transmission lines from the generating station to central grid. This saving in the transmission infrastructure is in addition to the saving in energy loss due to reduced transmission path from distributed energy sources to the micro-grid than that in the case of conventional centralized generation and transmission system ${ }^{[9]}$. The nearer the micro-grid location is to the consumer point, the lesser would be the initial cost of transmission line and the lesser shall be the recurring cost of energy loss in the transmission path. In essence therefore, the rural micro-grid systems with distributed generation feeding electric energy in remote or geographically difficult locations represent an innovation in the power system design and management over the conventional centralized generation systems.

The components of a representative type solar micro-grid system comprising Solar PV modules, Module tracking systems, Inverters, Step-up transformers and the grid connection interface are depicted in Figure (1). These systems achieve specific local goals, such as reliability, carbon emission reduction, diversification of energy resources, and cost reduction, etc. In essence, these systems provide cleaner, cheaper and affordable energy with more autonomous local controls suiting requirements of the users. The rural based solar micro-grid systems have the capability to address energy security problems and provide greater electricity access to the people in villages.

\section{User Friendly Features of ICT Enabled Smart Grid Summarized}

The power handling capacity and capabilities of a micro-grid system can be augmented by the smart grid system depicted in Figure (2) which is 'a system of systems' providing a larger, ICT enabled, power system infrastructure for the delivery of electricity. It is the power system containing 4. Multiple automated transmission and distribution systems, all operating in a coordinated, efficient, and reliable manner. Broadly speaking, the smart grid intertwines technologies delivering an electricity network with the coordination of electricity resources in an optimal manner and is flexible, accessible, reliable and economic. It facilitates the desired actions of its users that may include distributed generation, the deployment of demand side management and energy storage systems and the optimal expansion and management of grid assets. The additional features introduced by the smart grid inter-alia include digitization, customization, sustainability, resiliency, intelligence and flexibility as shown in Figure (3) indicating that the smart grid systems are the power systems of the coming years that shall provide better service through the utility to consumers ${ }^{[12]}$.

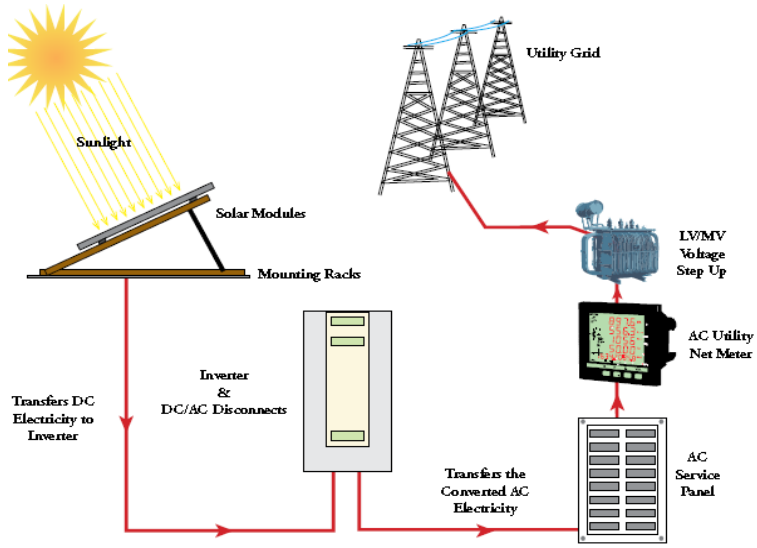

Figure 1: Components of a Solar PV Microgrid

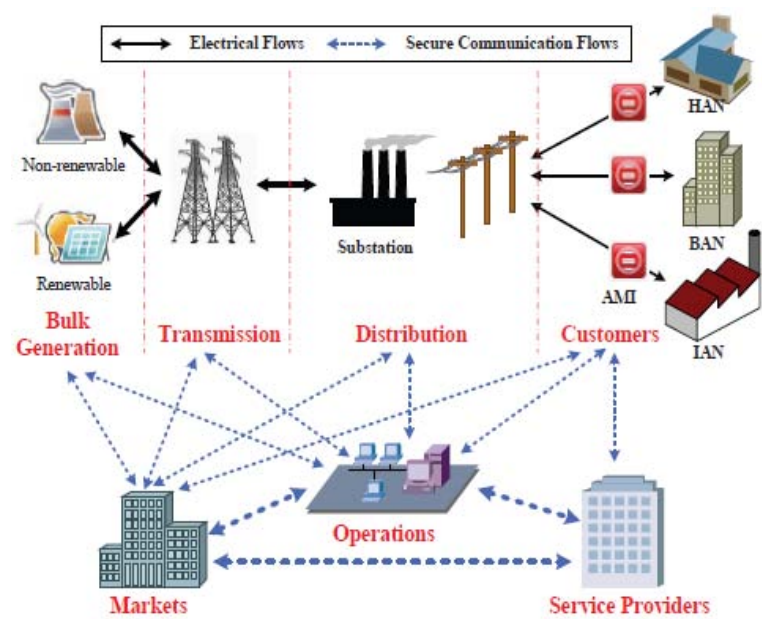

Figure 2: Components of A Smart Grid System 


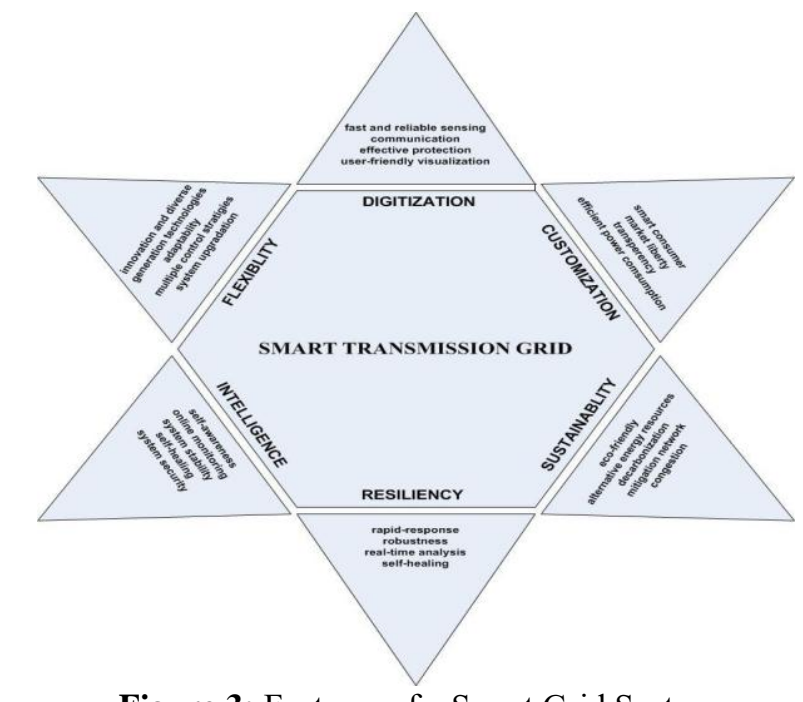

Figure 3: Features of a Smart Grid System

\section{Attributes of an Entrepreneur}

Entrepreneurship' is one of the principal mechanisms for the mitigation of unemployment and under-employment amongst educated youth. For success, the prospective engineer entrepreneur must coordinate knowledge and skills and keep abreast of the technologies, business market, skill requirement and fiscal policy issues related to the solar energy business. In addition, the engineer entrepreneur ought to do lots of homework for site selection, check proximity of the enterprise to transport facilities and power evacuation for establishing a micro-grid enterprise ${ }^{[5]}$. Attention must be paid on the cost, durability, effectiveness and the design of the important components, such as the solar inverter, transmission and distribution equipment and supporting switchgear and equipment which ought to be geared up as per demand and the local market and engineering procurement and commissioning (EPC) contractors etc. The entrepreneur should vigorously survey the human resource requirement and keep a database of the organizations willing to provide financial and technological assistance to the prospective entrepreneurs on convenient terms. The prospective entrepreneur must try to partner with reputed companies and institutions to develop mechanisms and maintain profitability and human resource development for entrepreneurial operations.

\section{Rebates and Concessions to Young Engineer Entrepreneurs under the National Solar Mission}

A plethora of opportunities await young engineer entrepreneurs to avail special incentives, subsidies and tax benefits from the Government side as MSMEs and Energy entrepreneurs to make them active partners in developing country's economy by enhancing electricity access in village clusters ${ }^{[6,7]}$.. The Jawaharlal Nehru National Solar Mission (JNNSM), offers a 10-year tax holiday for photovoltaic (PV) and thermal solar plants getting completed before 2020, reduced customs duty and zero excise duty on specific capital equipments, critical materials and project imports in addition to the grant of loans at cheap interest rates. These concessions and subsidies are meant to meet the challenges of ecologically sustainable growth and energy security and for fulfillment of the target of solar energy in villages and grid connected power by the National Thermal Power Corporation fixed at $100,000 \mathrm{MW}$ and 15, $000 \mathrm{MW}$ respectively by the year $2022^{[5,6]}$. The young engineer entrepreneurs must carefully understand the perspective, policies and incentives and its implications and derive optimum benefits in order to make their ventures business oriented and profitable.

In addition to acquiring the basic skills and knowledge in the undergraduate curriculum the prospective engineer entrepreneur should do some homework for site selection, proximity to transport facilities and power evacuation for setting up the enterprise ${ }^{[5]}$. Attention should also be paid to the components like solar inverters, transmission and distribution systems etc. which shall have to be tailored as per demand, the available and suppliers, engineering, procurement and commissioning (EPC) contract ${ }^{[5]}$ etc. The entrepreneur should vigorously survey the human resource requirement and keep a watchful eye on the organizations willing to provide facilities of finance or technology or both to the entrepreneur on convenient terms. The entrepreneur must partner with the reputed companies and develop mechanism to maintain profitability of the entrepreneurial operation $^{[5] .}$.

\section{Skill Gaps in Curriculum and the Requirement to Abridge Gaps}

Wide gaps exist in the training imparted in the academic programs and that actually required by the utility service organizations at the undergraduate engineering, technician diploma and vocational levels. This is so because the institutions do not lay adequate emphasis on the much needed skills in the academic programs. These deficient components in the academic programs must be suitably abridged to cover gaps and develop human resource that the rural electricity services require. In particular, the modules related to installation, maintenance, entrepreneurship and business in solar industry and rural electricity services need special attention to fill gaps and provide reorientation to the programs. Technical institutions at all levels should come forward to sign MOU partnerships with the leading organizations in solar energy industry and the resource centers like IITs, NITs etc. to promote faculty interaction with the expert researchers for a more meaningful dissemination of the knowhow for harnessing emerging technologies for the public good. Workshops covering modules on techno-commercial aspects and skill training in the business should be created to revamp training and coverage of industry oriented programs to make engineering education entrepreneurship - oriented and more meaningful. The engineering institutes should closely liaise with industry and the institutes to explore internship for students in the solar research Centers, Labs, and facilitator agencies imparting training in entrepreneurship and MSMEs for creating skilled manpower and develop next generation solar energy entrepreneurs with attributes of constant learning, innovation, decision making, risk taking and the initiative and drive to succeed. It is time for the technical institutes to create 


\section{International Journal of Science and Research (IJSR) \\ ISSN (Online): 2319-7064}

Index Copernicus Value (2013): 6.14 | Impact Factor (2014): 5.611

entrepreneurs equipped with confidence, passion and inner urge to translate the dream of universal electricity access into reality in India. The course contents must be suitably structured to include professional training with modules on real time practice lab on solar PV technologies, photovoltaic system installation, photovoltaic business management, rooftop installation etc. etc.

The suggestion, however, does not imply that the improvements in the curricula and training be made the precondition to begin the creation and development of new enterprises by the young engineer entrepreneur. The improvements in the curriculum should, in fact, be a continuing process so that the objectives of the National Solar Mission meets thumping success paying rich dividends to the national economy and the future generations can share fruits of prosperity and success through the efforts of the young engineer entrepreneurs.

\section{Concluding Remarks}

India had committed universal electricity access by 2012, a stipulation the country has still to strive for till it is accomplished. Universal electricity access must also be the tenet of every civilized society, an objective of the Nation's Energy Policy, the goal of the National Solar Mission and one of the Millennium Development Goals envisaged by the UN. Both rural and the urban segments of society have the crying need to gain universal access in the country but perhaps the need for access in rural India needs more to be done in today's scenario. Electricity infrastructure with clean, hygienic, abundant and affordable solar energy source through the dedication and involvement of young engineers is the need of our times and this is what the author has asked the young generation of engineers to accomplish in this article.

To conclude, the small standalone solar micro-grid systems proposed for rural development are not really small, as these can substantially improve productivity and GDP contribution to the country. The creation of rural micro-grid utilities can provide synergy to the present levels of industrial production and export productivity from small industry which is at $45 \%$ and $40 \%$ respectively to make this country not only the energy leader but also the economic power due to its contribution in the new economic areas like agricultural, food processing, and engineering industry ${ }^{[10]} \cdot$ Such an effort shall even enhance employment avenues in villages giving multiplier effect to the rural economy through MSMEs and SMEs in the villages and bring improvement to the quality of life and prosperity in rural India.

\section{References}

[1] Energy Poverty: The Hidden Energy Crisis; Practical Action: Technology Challenging poverty. www.practicalaction.org

[2] Digital Government-Pathways to Delivering Services for the Future-an Accenture publication.

[3] B. Bowonder and Gopi Boddu, Internet Kiosks for Rural Communities: 8_digital pdf-adobe reader
[4] Sameer Sachdeva, White Paper On E-Governance Strategy in India; sachdeva_sameer@yahoo.co.in (from internet)

[5] Richa Chakarvarthy, How to enter Solar Grid Business; Electronics Bazaar, November, 2011; www.electronicsb2b.com;

[6] D.V. Avasthi ${ }^{1}$, Gajendra Singh ${ }^{2}$; Deploying Renewable Energy Microgrids To Improve India's Electricity Scenario: Challenges \& Opportunities; International Journal of Scientific \& Engineering Research, Volume 5, Issue 10, October-2014 648 ISSN 2229-5518.

[7] D.V.Avasthi ${ }^{1}$, Gajendra Singh $^{2}$; Inspiring Young Engineers to Establish Stand-Alone Micro-Grid Enterprises for the Mitigation of Power Crisis and Unemployment in India; International Journal of Science and Research (IJSR); Volume 3 Issue 8, August 2014 ISSN (Online): 2319-7064, Impact Factor (2012): 3.358

[8] Ashok Kumar Rajput, D. V. Avasthi, Durgesh Kumar, Variation of Estimated Insolation from East to West in Uttar Pradesh, India; International Conference on Innovative Applications of Computational Intelligence on Power, Energy and Controls with their Impact on Humanity (CIPECH14) 28 \& 29 November 2014.

[9] Swami Prakash Srivastava and Surat Prakash Srivastava, Solar Energy And Its Future Role In Indian Economy: International Journal of Environmental Science: Development and Monitoring (IJESDM)ISSN No. 2231-1289, Volume 4 No. 3 (2013)

[10]R. Arun Prasath, Renewable Energy Promotion and Training through SMEs in Rural India-Potentials and Challenges (Sept. 2012), Laboratory for Energy, Materials and Sustainability, Centre for Green Energy Technology: Pondicherry University

\section{Author Profile}

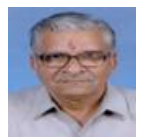

Prof. D.V. Avasthi received B.E. (Elect. Engg) and M.Sc. (Engg) Electrical degrees in 1974 and 1984 respectively from Aligarh Muslim University and University of Delhi. He served as teaching faculty in the Aligarh Muslim University from 1975 to 2006 and also as Training and Placement Officer and Entrepreneurship Trainer. Later after retirement, he was engineering teacher in the Mangalayatan University, Aligarh, Noida International University Noida and is presently a teaching faculty in the Swami Vivekanand Subharti University: Meerut. His areas of interest include Technology based Entrepreneurship Development, Solar Energy, Power Quality and Electromagnetics. 